Cad.Est.Ling., Campinas, (45):21-32, Jul./Dez. 2003

\title{
TEORIAS E CONCEITOS NA LINGÜÍSTICA COGNITIVA (IN)COMPREENSÕES
}

\author{
ANA FLÁVIA LOPES MAGELA GERHARDT \\ (UFRJ)
}

\begin{abstract}
We consider three important notions to Cognitive Linguistics - the notions of mental spaces, metaphor and prototypes, discussing their status as real theories, as they're usually taken, or as notions which must interact with others in equivalent conditions, or they should be treated as epiphenomena in the Cognitive Linguistics framework.
\end{abstract}

Na história das ciências da linguagem, a Lingüística Cognitiva é um dos acontecimentos mais recentes. O que a motivou de início, e na verdade a tem motivado até hoje, é o convite à investigação de fenômenos da linguagem deixados à parte pelos modelos teóricos considerados mainstream - as ambigüidades, as opacidades, os idiomatismos, o "sentido figurado", devido à crença tradicional de que apenas os fatos sistemáticos e sistematizáveis corresponderiam às evidências de como as línguas e a mente funcionam. Esse reposicionamento teórico é um fator presente na gênese de novas agendas descritivas e tem atendido, em princípio, à solicitação de uma justificativa para a existência da Linguiística Cognitiva como disciplina que investiga processos estáveis e fenômenos da cognição subjacentes à produção e interpretação dos significados e da gramática, sobretudo diante das teorias gerativas, que também definiriam semelhante projeto de trabalho.

Mas as diferenças não se limitam a esse novo olhar. Há, ainda, um outro dado fundamental, caracterizador da Lingüística Cognitiva como teoria não-formalista de investigação da linguagem, que é o tratamento da forma lingüística como meio de acesso ao significado, interagindo com variados processos cognitivos, em contraposição à idéia dos elementos lingüísticos como responsáveis por toda a elaboração representativa de conceitos, fatos etc. que se queira transmitir ou construir via linguagem. Ao pressupor a importância daqueles processos, e o léxico e a gramática como sua manifestação e gatilho, a Lingüística Cognitiva faz emergirem e se associarem aspectos relacionados à mente humana e seu funcionamento, os quais, em princípio, são objetos de estudo de disciplinas como a Psicologia Cognitiva e a Filosofia; outrossim, busca definir aparatos descritivos que favoreçam a visão da linguagem como pista para a construção do significado, a par de uma série de princípios cognitivos e pragmáticos, todos elevados, nesta perspectiva, a uma mesma e privilegiada condição epistemológica. O cenário então se torna propício para a abertura de um espaço interdisciplinar, em que se pode levar em conta a significação lingüística não como a tradução referencial de uma realidade pressuposta, mas sim como uma forma de representação de valores e modelos de mundo, com toda a sorte de experiências que nele e a partir dele podemos vivenciar.

E, de fato, testemunhamos, no atual estágio da Lingüística Cognitiva, um fértil intercâmbio entre os estudos da linguagem stricto sensu e pesquisas variadas em Psicologia Cognitiva e Filosofia, como já afirmamos, e também em Antropologia Evolutiva, Microssociologia, Neurofisiologia e diversas outras áreas de conhecimento, as quais, por décadas, têm mantido com a Lingüística um saudável diálogo. Como efeito desse intercâmbio, tem-se a produção de trabalhos hoje já clássicos, em que podemos evidenciar a presença de diversas pesquisas em outras áreas, cujos resultados, 
associados a conceitos elaborados e desenvolvidos dentro de disciplinas relacionadas à linguagem, concorrem para a elaboração cada vez mais harmonizada e completa da Lingüística Cognitiva como um corpo teórico complexo, sofisticado, epistemologicamente fundamentado e capaz de sustentar estudos e conclusões sobre a organização das línguas.

O propósito deste texto é o de debruçar-se brevemente sobre o panorama da Lingüística Cognitiva como esse corpo teórico, ou seja, como uma organização de conceitos que ora provieram de outras disciplinas, ora se desenvolveram no seio da investigação da linguagem, mas que juntos podem favorecer a composição de uma unidade teórica. Provavelmente pelo fato de a Lingüística Cognitiva ser um desenvolvimento relativamente recente, a condição muitas vezes conferida a alguns desses conceitos é a de que eles prefigurariam teorias completas, encaixando-se assim na visão de corpo teórico conforme colocada acima. Por esse motivo, enfocamos especificamente três noções que têm sido consideradas "teorias" em variados estudos e discussões voltados para os problemas da cognição humana e das suas formas de expressão lingüística: a de espaços mentais, a de metáfora e a de protótipo. Vários outros conceitos centrais se encaixam nesta problemática, dentre os quais podemos citar a mesclagem, o esquema imagético, o enquadre, a construção gramatical etc., também freqüentemente tratados como teorias; o enfoque nos conceitos citados acima se justifica porque nos três casos estaremos tratando de divisores de águas no processo de construção de uma ciência da linguagem como processo sócio-cognitivo, e também porque o seu estudo motiva-nos à observação da organização interna da Lingüística Cognitiva e do valor relativo dos conceitos que a compõem na formação de um organograma de estudo e trabalho. Nessa observação, poderemos não obstante reconhecer que conceitos já tidos como centrais no passado hoje já não gozariam deste status, diante do natural desenvolvimento da disciplina proporcionado por pesquisas mais recentes e pelo intercâmbio com outras áreas de conhecimento.

Passemos, pois, à reflexão pretendida sobre os conceitos em foco neste texto.

O conceito de espaços mentais, segundo se observa na literatura, aparece pela primeira vez em 1978, de acordo com Fauconnier (1994[1985]: xxv). O autor, em sua obra pioneira e completamente dedicada ao assunto, utiliza o termo "teoria dos espaços mentais" (ibid.), mas logo depois consideraos como "construtos teóricos", afirmando que eles não podem ser caracterizados "independentemente da teoria de que fazem parte" (ibid.). E, realmente, em página anterior, Fauconnier reconhece os liames entre noções relacionadas a experiências lingüísticas, cognitivas, interacionais e sócio-culturais que, em conjunto, configuram uma visão do que tomamos como "mundo real", e estabelece todas essas noções como partes de teorias maiores.

No cerne da Lingüística Cognitiva, o advento dos espaços mentais exerce, a par da noção de metáfora como processo cognitivo geral, o papel metodológico de reverter as expectativas do que se propunha ser o objeto de estudo das ciências da linguagem, ao focalizar justamente as construções marginais, opacas e ambíguas, e, com isso, abrir caminhos para a investigação do que Fauconnier (op. cit.) denomina backstage cognition: um universo de processos e fenômenos desconsiderados pelas visões referenciais do significado, as quais relacionam representações a condições de verdade, e por isso não dão conta de uma série de fatores cognitivo-pragmáticos participantes da organização da gramática. Através da observação dos espaços mentais construídos e manifestados em conjunto com determinados usos lingüísticos, é possível evidenciar relações de identidade entre referentes distintos ou entre um mesmo referente reenquadrado no desenrolar do discurso.

Dessa forma, firmam-se os espaços mentais como meio de investigação de processos cognitivos numa perspectiva mais ampla, de sorte que seu estudo não deve redundar em um fim em si mesmo, antes precisa ser feito com a consciência de que eles organizam localmente informações vinculadas a campos de experiências de naturezas diversas, sobretudo modelos cognitivos idealizados; além disso, sabemos que a deflagração de espaços mentais se faz muitas vezes com o auxílio dos chamados space builders, elementos lingüísticos que nos auxiliam a definir em que tipos de universos as 
relações entre referentes devem ser compreendidas. Portanto, o estudo dos espaços mentais não pode ser feito sem considerarmos essas bases de conhecimentos, e a partir disso podemos também concluir que a própria constituição da Lingüística Cognitiva como modelo teórico perpassa uma hierarquização de noções epistemológicas, teóricas e operacionais, entre elas os espaços mentais, que se apresentam como um poderoso aparato descritivo, mas não têm fôlego suficiente para sobreviver sem a contribuição e co-participação de outros aspectos relacionados à formação dos domínios estáveis e locais de experiências, como bem já havia afirmado Fauconnier (op.cit.). Em outras palavras: discussões e descrições das formas lingüísticas que se baseiam tão-somente na noção de espaços mentais não são suficientes para uma tentativa de explicação da natureza da linguagem. Por isso, embora Fauconnier (op.cit.: xix) tenha citado o termo "teoria dos espaços mentais", não parece tê-lo feito com a intenção de enquadrar uma teoria completa, porque, em vários outros momentos, reitera o estatuto de conceito que os espaços mentais representam relativamente a tantos outros dentro da Linguística Cognitiva (p. ex., em xxxi). Assim, podemos concluir pela impossibilidade de se tratar a idéia de espaços mentais sem os alicerces da teoria em que se inclui.

Essas afirmações se comprovam com a observação de alguns trabalhos destinados a descrever certos fatos da gramática em relação aos espaços mentais que constroem, e que, sem vincular efetivamente a descrição a uma teoria definida da linguagem, não logram reconhecer, na sua prática, os espaços mentais como cenários de enquadramento da realidade. Por isso, tais trabalhos não poderão identificar as condições que permitem e determinam a construção dos espaços mentais constatados, porque não explicam as regularidades (entendidas aqui como os processos cognitivos gerais: conceptualizações mais básicas e mapeamentos cognitivo-pragmáticos) envolvidas nas relações referenciais dentro de e entre espaços mentais. Um exemplo de trabalho deste tipo é a Tese de Cutrer (1994), que supõe uma "teoria dos espaços mentais" para a descrição de construções e relações entre espaços mentais motivadas pelo uso de tempos verbais, e produz um trabalho de ampla abrangência descritiva, mas que não chega a discutir as dimensões de experiência mais básicas envolvidas nas representações abordadas pela autora; na verdade, essa nem chega a ser a sua intenção. Por isso, a Tese de Cutrer é um exemplo bastante evidente de que a noção de espaços mentais, como outras noções evocadas na Lingüística Cognitiva, é um poderoso instrumento de estudo da backstage cognition, mas não é uma teoria - é um conceito e, em termos heurísticos, é um aparato descritivo que precisa interagir com outras noções, conceitos e instrumentos para cumprir a tarefa fundamental da Lingüística Cognitiva, que é observar as representações léxico-gramaticais das relações entre mente, linguagem e mundo.

Também pertencente desde o início ao universo dos estudos em Lingüística Cognitiva, o conceito revolucionário de metáfora emergiu naquela disciplina não mais como mero tropo, mas sim assumindo um estatuto mais amplo - o de projeção entre domínios de experiências. Embora já haja registro de algum interesse pela metáfora em tratados de Aristóteles, seu valor tem sido, ao longo da história, considerado puramente "ornamental" (termo de Ortony, 1993:03), num universo de estudos da linguagem que prima pela separação entre o "sentido literal" das palavras em contraposição ao "sentido figurado", habitat das obscuridades referenciais. Para além desse escopo, no início do século vinte já se tem notícia, em Richards (1936, apud Ortony, op.cit.), de propostas de investigação sistemática do fenômeno metafórico, para, já na década de setenta, promoverem-se estudos e seminários interdisciplinares sobre o assunto (um deles resultando na compilação organizada por Ortony, op. cit.). Entretanto, como marco na história da Lingüística Cognitiva, consagrou-se o trabalho de Lakoff \& Johnson (1980), que propiciou um profundo e fértil repensar sobre as questões do significado, firmando-se em pouco tempo como a mola mestra daquele modelo teórico, dada a consideração da metáfora, em estudos de primeira hora, como processo central da cognição humana.

Variados estudos em Lingüística Cognitiva beneficiaram-se da idéia de metáfora relacionada a domínios de conceptualizações, entidades e experiências. Em decorrência disso, inúmeros outros 
conceitos relacionados a esses domínios têm sido desenvolvidos e/ou reformulados, estando agora enquadrados como projeções intra e interdomínios, como por exemplo as metonímias (Fauconnier, op. cit.) e o sujeito cindido (Lakoff, 1996). A partir dessa visão da metáfora, em associação com diversos conceitos, principalmente os outros dois que estão sendo avaliados neste texto, passou-se a compreender a construção e expansão do significado e da gramática com base na radialidade, motivada muitas vezes por projeções metafóricas.

O progresso teórico trazido pelos estudos que consideravam a metáfora como participante da organização de categorias, das relações entre significados e da estruturação gramatical levou à instituição de que o que elas são basicamente - uma projeção interdomínios - se configura como a capacidade cognitiva humana mais importante. Entretanto, hoje podemos reconhecer que, embora decerto a metáfora seja uma projeção interdomínios, cujo estudo nos permite compreender as formas possíveis de conexão entre universos de experiências, nem toda projeção interdomínios é metafórica. Por exemplo, junto à noção de espaços mentais, definiu-se, ainda na década de noventa, um tipo específico de projeção denominado mesclagem (Fauconnier \& Turner, 1993 e, mais recentemente, Fauconnier \& Turner, 2002, entre inúmeros outros trabalhos), processo inicialmente reconhecido como uma integração conceptual que envolveria diferentes espaços mentais como domínios-fonte, a fim de se construir um espaço-alvo composto pela combinação de elementos dos espaços originários mediante os domínios de experiência em jogo no discurso. Em princípio, considerou-se a mesclagem como um "processo central da gramática" (Fauconnier \& Turner, 1993), da mesma forma como o foi a metáfora em outros tempos; atualmente, toma-se a existência da mesclagem como fenômeno ainda mais abrangente, presente em diversos domínios conceptuais, e, inclusive, participando como peça fundamental no desenvolvimento cognitivo e lingüístico do ser humano, podendo tanto estar presente nas relações entre bases de conhecimento, quanto motivar a expansão de construções gramaticais (Fauconnier \& Turner, 2002).

Observe-se que, semelhantemente ao que discutimos no caso dos espaços mentais, a noção de metáfora propiciou o alcance de horizontes mais amplos para a compreensão da linguagem, mas tãosomente se relacionada a outros conceitos tidos como bases de conhecimento sócio-cognitivo de construção e expansão do significado lingüístico. Portanto, também neste caso é inoportuno caracterizar-se uma "teoria da metáfora", já que se trata aqui também de um conceito que interage com outros na constituição de um arcabouço teórico relacionado à cognição, e não de um conjunto de conceitos organicamente estruturado. E mais: a metáfora, sendo uma relação entre entidades, eventos e idéias em domínios de diferentes níveis, não raro é tomada como a própria relação entre domínios inteiros, quando se admite, por exemplo, o tempo como metáfora do espaço.

$\mathrm{Na}$ verdade, estamos inclinados a reconhecer a metáfora, a mesclagem e as outras relações referenciais entre espaços mentais como aspectos de um fenômeno projecional mais fundamental ainda, que também subjaz à relação entre domínios de experiência como um todo, como espaço e tempo, espaço-tempo e causalidade/finalidade etc., esquemas imagéticos e significados mais abstratos a eles associados, como o que ocorre entre o esquema dentro-fora (Johnson, 1992) e os significados de posse/existência (Gerhardt \& Pinheiro, inédito), e, até, na questão do desenvolvimento lingüístico, as diferenças e relações entre fala e escrita, bem como os vínculos entre as demais semioses: trata-se da redescrição representacional (Karmiloff-Smith, 1992), possivelmente o procedimento cognitivo humano mais essencial, para além (ou aquém) do que já se disse sobre a metáfora e a mesclagem. Perfeitamente enquadrada no paradigma sócio-cognitivo, a redescrição representacional se produz com o rastreamento de habilidades e informações inatas e adquiridas a fim de que a pessoa as combine, as adapte a diferentes domínios cognitivos e as reconfigure para a resolução de novos problemas, num processo de crescente flexibilidade e manipulabilidade dos significados de qualquer natureza. Nesta operação, o acesso ao conhecimento faz-se através da exploração intra e interdominial de informações inicialmente apropriadas a um determinado universo de experiências, a fim de que 
elas sejam aproveitadas em outros universos afins. Dentro de uma prescrição epistemológica que pressupõe o relacionamento entre os diferentes sistemas da cognição, em contraponto às perspectivas modulares sobre a mente humana, a redescrição representacional está ligada intimamente ao desenvolvimento e expansão cognitiva e lingüística, desde a infância tenra até a idade adulta, quando marcará presença em qualquer forma de aprendizado ou recodificação de representações, através de procedimentos de análise e seleção de informações que acarretam uma projeção parcial de elementos de um domínio a outro, fato assumido como inerente à natureza da metáfora e da mesclagem, à expansão categorial e às relações entre diferentes semioses.

A constatação da existência da redescrição representacional tem sido feita por vários autores, que a reconhecem e a discutem como processo central na cognição humana, conferindo-lhe diferentes denominações, mas convergindo para uma mesma função: o "acesso entre módulos/domínios mentais", para Rozin (1986); o "módulo da meta-representação", para Sperber (1994); a "fluidez interdominial”, para Mithen (2002[1996]); o "mapeamento/projeção entre domínios", para Carey \& Spelke (1994) e Salomão (1997; 1998; 1999); o “aprendizado construtivo”, para Quartz \& Sejnowski (1997). Em contraponto às teorias que postulam o encapsulamento dos módulos mentais, as quais defendem justamente a possibilidade de "erros comportamentais" na definição da essência daquilo que vemos ou experimentamos (Mithen, 2002[1996]:92), os estudos sobre a redescrição representacional lato sensu alcançam uma amplitude interdisciplinar, na medida em que, mediante o seu ponto de vista, podemos situar as particularidades da mente humana relativamente às de outras espécies, bem como as diferenças qualitativas ao longo do desenvolvimento ontogênico humano, em termos cognitivos e neurobiológicos. No que diz respeito à linguagem, inaugura-se a possibilidade de investigações para além do que se supõe serem processos metafóricos, referenciais, de mesclagem etc., e abre-se o caminho para reconhecimentos mais aprofundados acerca das relações intersemióticas envolvendo a expressão lingüística em suas diferentes modalidades e das interseções entre a linguagem e demais representações.

Diante do exposto, estamos propondo que a metáfora, a mesclagem, as relações entre bases estáveis de conhecimento, bem como as relações entre bases estáveis e locais, são facetas constitutivas do processo mais geral da redescrição representacional. Decorrentemente, nossa argumentação nos faculta propor para a metáfora não o caráter de teoria autônoma, mas sim o status de conceito articulado a outros relacionamentos intra e interdomínios, semelhantemente ao que se afirmou sobre os espaços mentais.

O terceiro conceito que é objeto de interesse neste texto, também necessariamente presente em trabalhos da Lingüística Cognitiva, é o de protótipo, surgido seminalmente em Rosch (1973, quando o termo ainda aparecia entre aspas), como parte de pesquisas em Psicologia Cognitiva. Assim como já discutimos acerca dos conceitos anteriores, trata-se aqui também de um elemento que reorienta epistemologicamente modelos tradicionais, no caso, o da categorização clássica, cujos moldes remontam a Aristóteles. Mediante a noção de protótipo, tornou-se possível evidenciar, no processo de categorização, determinados princípios abstratos que vão além daqueles estabelecidos pelas taxonomias de inspiração clássica, como a eliminação das exigências de simetria de estatuto entre os elementos de uma categoria e de delimitação precisa de fronteiras categoriais internas e externas. Considerando-se um protótipo categorial, ou seja, um suposto elemento que conteria o maior número de atributos em comum com outros membros relacionados, supôs-se poder sinalizar como são as estruturas das representações mentais em termos de categorização: as categorias seriam planejadas não pelos seus aspectos em si, mas pelo que percebemos deles, e esta percepção não conta com um universo caótico, mas sim com uma organização altamente hierarquizada, que dependeria intimamente de protótipos previamente estabelecidos.

Observe-se, com o que é dito acima, o caráter pré-teórico da noção de protótipo, que emerge como manifestação de eventos cognitivos gerais. No caso específico dos protótipos, a detecção dos 
seus aspectos foi realizada primariamente na Psicologia Cognitiva e depois adotada, naturalmente, pelas pesquisas em categorização lingüística; dentre esses trabalhos, o grande clássico é Lakoff (1987), embora Givón (1984) já tivesse discutido anteriormente a noção, denominando-a "teoria dos protótipos".

$\mathrm{Na}$ Lingüística, em específico, a idéia de protótipo no estudo da categorização lingüística relaciona-se ao reconhecimento de uma instância categorial prototípica, fazendo emergir, como corolário, a atribuição de diferentes estatutos para os elementos a ela relacionados, provocando indagações a respeito dos limites de consideração do que pertence a uma dada categoria, bem como questionamentos sobre o que define as fronteiras categoriais. $\mathrm{O}$ impacto que tal conceito provoca sobre a idéia do que é categoria muda a visão quanto à forma como compreendemos o mundo, mudando também a visão quanto à forma como assumimos os significados, os valores, os ambientes, a linguagem. Essa alteração de perspectiva, além de trazer o homem para dentro do processo de construção cognitiva, situa-se antipodamente a uma série de idéias sustentadas pelo modelo clássico e formalista de raciocínio (Lakoff, op.cit.: 09), que têm como base a existência de uma visão divina do mundo, determinadora de todas as noções. Portanto, novamente estamos diante de uma concepção vital para o desenvolvimento da Lingüística Cognitiva, porque ela amplia o seu escopo de atuação relativamente a uma de suas disposições mais fundamentais, que é o estudo da categorização, incrementado pela noção de protótipo categorial e seus corolários.

Nossa discussão acerca da noção de protótipo não se limitará ao caso de estarmos ou não tratando de uma teoria, mas também envolverá a própria pertinência do conceito ora em questão para o alcance dos objetivos da Lingüística Cognitiva, que estão voltados para a investigação dos fenômenos gerais que governam a constituição da linguagem e da organização dos seus elementos em variados níveis de análise. E, tendo esses objetivos em mente, podemos afirmar que o estudo das categorias centralizado nas evidências de instâncias prototípicas não perpassa as metas daquela disciplina, por não se envolver com os domínios de atuação e conceptualização onde sobrevivem os fundamentos para a organização categorial. Por isso, embora evidentemente se relacione com as categorias, a constatação da existência de protótipos não se presta a uma explicação de como elas se formam e se expandem.

Esta afirmação, hoje possível graças ao advento de um arcabouço teórico-epistemológico definido para os estudos em Lingüística Sócio-cognitiva, não é uma completa novidade nas ciências da cognição, já que a própria Eleanor Rosch chegou a questionar, em plena emergência da abordagem do fenômeno categorial em termos de protótipos e efeitos prototípicos, o que eles de fato seriam, bem como o que não seriam; nesse questionamento, Rosch considerou o fato de que nem todas as categorias apresentam protótipos definidos, a representatividade dos protótipos relativamente às categorias de que fariam parte, e a sua participação em processos cognitivos de identificação de categorias (Rosch, 1973). Não obstante, no atual estágio de entendimento da Lingüística Cognitiva, podemos amadurecer estes questionamentos, repensando a noção de protótipo e seu possível papel em descrições fidedignas aos moldes fundamentais da Lingüística Cognitiva, a partir do reconhecimento prévio de dois fatos: (i) que, entre a definição do que é o melhor exemplo de uma categoria para a sua adoção como eixo de organização categorial, ocorre um salto descritivo muito acentuado; (ii) que não é possível reconhecer um suposto elemento prototípico como o alicerce de uma dada categoria, já que ele não participa da sua construção e expansão, antes emerge como um epifenômeno, ou seja, como evidência de sua organização e gradualidade, daí não fazer sentido a assunção de que as categorias se fundam com base em um dos seus elementos, por mais representativo que ele seja.

Construímos nosso raciocínio levando em conta que a própria noção de protótipo, surgida em searas de pesquisa não direcionadas ao estudo da linguagem num sentido estrito, emergiu e se desenvolveu atrelada a uma preocupação acerca do seu reconhecimento e identificação num domínio 
perceptual consciente de ordenação de mundos; este pormenor está presente em toda a obra de Rosch dedicada ao fenômeno, desde os trabalhos iniciais até os mais recentes, em que se vêem claramente os protótipos como atributos relacionados à percepção consciente das coisas bem como à saliência perceptual dos atributos dos elementos considerados pelos indivíduos. Permeia o trabalho de Rosch o cuidado em salientar que se está no âmbito de uma estrutura de mundo percebido, mas num nível diferente daquele em que se detectam as bases estáveis de conhecimento que fundamentam a formação das categorias. Isso ocorre porque é possível identificar patamares inconscientes e conscientes (ou seja, cognitivos e metacognitivos) de experiência e construção cognitiva: naqueles, estão constituídas gestalts altamente sistematizadas e de base corporificada, cuja formação repousa na abstração das formas de contato que podemos estabelecer com o espaço e as entidades à nossa volta; nestes, as pessoas reconhecem as características das coisas, reunindo-as em grupos de acordo com as semelhanças que podem reconhecer explicitamente. A existência desses dois patamares justifica-se nas diferenças, a par das relações, que há entre a mente como espaço de construção e organização das bases de conhecimento estáveis que subjazem à formação das categorias e da gramática, e a consciência, que é o locus do processo de reflexão sobre as atividades da mente, ou seja, é o nível da mente onde informações estruturadas em outras instâncias emergem à condição de raciocínio, e como tal são usadas, de forma tal que não será necessário haver uma concordância entre o que se pensa estar fazendo, organizando, interpretando, categorizando etc., e o que efetivamente se faz, se organiza, se categoriza etc ${ }^{1}$. E de fato temos constatado que o que as pessoas acreditam estar executando, com seu pensamento e sua linguagem, nem sempre corresponde efetivamente a realizações cognitivas, e isso inclui não apenas a construção das bases categoriais, mas também processos como o parsing, a coordenação da atividade visual, a interação entre os diferentes níveis de memória, bem como outros fenômenos relacionados ao processamento de informação.

O que está dito acima nos permite afirmar que mente e consciência são diferentes domínios de experiências, porque regidos por diferentes determinações. E, no caso, interessam à Lingüística Cognitiva os mecanismos e padrões da mente, e não da consciência, ou seja, mecanismos e padrões sobre os quais o falante não tem domínio consciente nem acesso imediato, mas pode acionar automaticamente sempre que for necessário, inclusive para reconhecer um elemento como fazendo parte ou não de uma categoria. Protótipos, por sua vez, são construtos da consciência, portanto serão elementos interessantes a estudos em um nível de percepção das coisas que não está no foco da Lingüística Cognitiva. Portanto, tomar a noção de protótipo como fundamento para a organização categorial não vai levar a identificações e análises fidedignas dos processos sócio-cognitivos relacionados às categorias; no mínimo, estaremos chamando de fundamento o que em muitos casos é outra coisa, porque o elemento prototípico é tão-somente um dos componentes da sua categoria, e não o seu deflagrador, já que, na verdade, a organização categorial se funda em bases estáveis de conhecimento cognitivo-pragmático: esquemas imagéticos e demais construtos genéricos; modelos cognitivos idealizados; enquadres léxico-gramaticais; molduras comunicativas. Assim, na essência das categorias, não encontraremos protótipos, mas sim padrões corporificados contra os quais uma verdadeira checagem de pertinência é feita pela mente.

A noção de protótipo foi importante à Lingüística Cognitiva por levar à reflexão de que as categorias não se organizam referencialmente, mas sim subjetivamente, o que proporcionou à disciplina um poderoso alicerce descritivo. Mas, por pertinente que seja a evolução ocasionada pelo advento da noção de protótipo para as teorias da cognição e da linguagem, hoje podemos observar

\footnotetext{
${ }^{1}$ Cientes das dificuldades inerentes ao tratamento do que pode alinhar-se sob o rótulo "consciência", adotamos a definição proposta por Block (1995:229), que se afina com a visão que assumimos para as relações entre consciência e mente: "a consciência deve ter, de alguma forma, a propriedade de permitir que a informação representada no cérebro (sic) seja usada no raciocínio, na comunicação e nas ações racionalmente conduzidas" (tradução nossa).
} 
que a grande diferença que tal noção nos proporcionou diz respeito, em última instância, não a uma oposição entre a visão clássica das categorias, a saber, como conjuntos estanques de elementos que nelas se inserem mediante padrões de necessidade e suficiência, e uma categorização baseada na visão de mundo que as pessoas supõem ter, mas sim a uma oposição entre a categorização nos moldes clássicos e aquela que se organiza mediante bases estáveis de conhecimentos, de forma tal que não se nega, nesta abordagem, a organização gradual entre os elementos das categorias, mas se afirma que essa gradualidade relaciona-se a padrões mais ou menos corporificados, e não a elementos/ instâncias mais ou menos prototípicos.

As consequiências dessa alteração de perspectiva sobre o estudo das categorias gramaticais conduzem à assunção de que a organização categorial e o próprio significado das formas lingüísticas são atributos que escapam à consciência, porque, para a formação das categorias, concorrem padrões internalizados de compreensão das coisas que não passam pelo crivo das organizações de base perceptual-consciente; este talvez seja um dos motivos pelos quais haja tanta dificuldade em lidar com o significado das coisas em linguagem.

Poderíamos nos perguntar se há dois níveis de estruturação categorial na gramática, um cognitivo e outro metacognitivo. Acreditamos que não, porque o que a percepção consciente julga qualificar corresponde, freqüentemente, a folk theories, e não a evidências de representação gramatical; entretanto, sabendo que o compartilhamento de concepções acerca de um mesmo fenômeno ou entidade relaciona-se, evidentemente, a bases estruturadas de conhecimentos comuns, podemos postular que a percepção consciente interessa à Lingüística Cognitiva na medida em que é tomada como ponto de partida para investigações mais acuradas e fidedignas aos alicerces sócio-cognitivos da gramática. Adotando esse procedimento, o pesquisador em Lingüística Cognitiva não raro percebe que os falantes reconhecem, para as formas gramaticais, significados bastante diferentes daquilo que a pesquisa evidencia como sendo o significado tido como conceptualização sócio-cognitiva. Diante disso, podemos supor que uma abordagem interessante para esse problema associaria os julgamentos dos sujeitos às redescrições representacionais necessárias para se chegar às suas percepções conscientes. Por exemplo, Gerhardt (2002) define, para o significado presente constituindo uma categoria gramatical do português, a consideração da simetria cognitiva, a saber, a condição de presença e visualização mútua entre os falantes no momento da enunciação; a apreensão deste significado partiu do senso comum que as pessoas assumem para o presente, que é a simultaneidade entre evento e discurso, mas certamente dele se distanciou sobremaneira, graças ao reconhecimento do tempo como redescrição do espaço, relação percebida entre o senso comum acerca do tempo presente - o agora, e um valor mais básico, espacial - o aqui. Tendo sido realizada uma pesquisa ainda atrelada à suposição de usos prototípicos para a forma do presente, não obstante chegou-se não a um protótipo, porque o que se buscou não foi uma representação da consciência, mas sim as bases estáveis de conhecimento corporificadas da categoria, que são construtos da mente.

Dessa forma, o tratamento que a noção de protótipo deve receber nos estudos em Lingüística Cognitiva é diferente do que temos proposto para as duas outras noções consideradas neste texto, que necessitam ser repensadas, mas se fazem verdadeiramente pertinentes aos projetos cognitivo e sócio-cognitivo de estudo da linguagem, interagindo com outras noções na constituição de uma base unificada de observação da linguagem. A noção de protótipo, longe de constituir uma teoria autônoma, sequer caberia nessa base teórico-descritiva; mas, levando-se em conta que o estabelecimento de protótipos é sensível sobretudo a fatores e contingências contextuais e culturais, como tem sido salientado na literatura a respeito do fenômeno, podemos reconhecer uma pertinência central do seu estudo no âmbito da Psicologia Social, da Microssociologia ou da Antropologia Linguística, que verificariam os elementos em jogo no estabelecimento de diferentes protótipos para categorias análogas em diferentes culturas, e como diferentes contextos e necessidades comunicativas definiriam diferentes protótipos relativamente a um mesmo conjunto de elementos (cf. Rosch, 1999:65 passim). 
Já afirmamos neste texto que os problemas identificados no uso das noções de espaços mentais, metáfora e protótipos podem ser justificados com o recente desenvolvimento da Lingüística Cognitiva, que passa por um processo, ainda, de acomodação e comprovação da pertinência (ou não) de algumas de suas noções. Tanto que há, além disso, outros conceitos cuja importância permite a reivindicação de instâncias apropriadas no corpo (ou não) da teoria: é o que ocorre, por exemplo, com as construções gramaticais, que apenas recentemente passaram a ser objeto de estudo sistemático. Neste quadro, a existência de eventuais incompreensões faz parte da afirmação da Lingüística Cognitiva como um modelo teórico epistemologicamente situado entre as disciplinas voltadas para a linguagem. Mas, seguramente, as incompreensões ocorrem ao lado de variadíssimos acertos analíticos e teóricos nos estudos realizados em todo o mundo e também no Brasil, onde já há grupos de pesquisa consagrados, com projetos orgânicos de descrição do português que primam pela não reprodução de modelos e determinações de escolas estrangeiras.

É o caso da proposta de estudo sócio-cognitivo da linguagem, desenvolvida basicamente em Salomão (1997; 1998; 1999), e tomada como orientação de trabalho em Miranda (2000) e Gerhardt (2002), bem como em outras pesquisas ainda em andamento. Buscando uma integração de conceitos, a postulação sócio-cognitiva de investigação dos fenômenos da linguagem não assimilará a fluidez do material teórico com que trabalha, já que isso ocorre quando as noções são trabalhadas em isolado. Diante do risco de incompreensão oferecido pelas formulações discutidas neste texto, a Lingüística Sócio-cognitiva marca seu espaço estabelecendo os papéis relativos entre, de um lado, bases estáveis de conhecimentos, constituídas como estruturas de memória coletiva, de fundamento gestáltico e sócio-cultural, como os modelos cognitivos idealizados, esquemas imagéticos e as molduras comunicativas, todos já citados neste texto, e, de outro lado, a língua, ela própria também uma base estável de conhecimentos, como instrumento que marca a perspectiva de compreensão de entidades, fatos, opiniões etc. envolvidos nos discursos, enquadrando-os relativamente aos universos de práticas e experiências acessados pelos interlocutores para efetivar os significados em jogo numa circunstância de comunicação. Essas bases interagem e enquadram-se em dimensões locais de experiência - os espaços mentais, que organizam em cada momento do discurso os referentes reconhecidos mediante as bases estáveis, marcando as suas relações espácio-temporais e identificacionais. A esses conceitos somam-se as construções gramaticais constituindo o nível de análise propício ao entendimento da linguagem como reveladora de significados de natureza cognitivo-pragmática. A tomada de observação das formas lingüísticas como construções conferirá ao arcabouço sócio-cognitivo a possibilidade de presença em estudos de caráter eminentemente gramatical, favorecendo as observações de como a estrutura da gramática pode ser representativa de expansões decorrentes da capacidade humana de redescrição representacional, incluindo-se aí as expansões de base metafórica. Outrossim, a possibilidade de as construções (ou instâncias construcionais) se relacionarem em diferentes graus de prototipicidade favorece, como ponto de partida, a detecção de experiências humanas mais essenciais na base da formação e expansão da linguagem.

Dado que, como dissemos, o campo das investigações sobre a natureza da linguagem diante das demais formas de cognição se nos mostra ainda favoravelmente desbravável, e, pelo alcance que o projeto sócio-cognitivo bem como outras postulações de mesma definição epistemológica podem assumir, torna-se extremamente interessante ao pesquisador da área buscar mais e melhores compreensões no estudo da linguagem bem como de outros processos de significação, tendo em conta, evidentemente, uma qualificação integradora para as noções discutidas nas teorias. Essa busca, dentro da Lingüística Cognitiva, é uma comprovação de que a História das ciências da linguagem ainda está sendo feita, e que muitos fenômenos ainda podem ser (re)descobertos. 


\section{REFERÊNCIAS BIBLIOGRÁFICAS}

BLOCK, N. (1995). On a confusion about a function of consciousness. Behavioral and Brain Sciences 18 (2): 227-287.

CAREY, S., SPELKE, E. (1994). Domain-specific knowledge and conceptual change. In: HIRSCHFELD, L.A., GELMAN, S. A. (eds.). Mapping the Mind: domain specificity in cognition and culture. Cambridge: University Press.

CUTRER, M. (1994). Time and tense in narratives and in everyday language. Ph.D. dissertation. University of California at San Diego.

FAUCONNIER, G. (1994[1985]). Mental spaces. Cambridge: University Press.

\& TURNER, M. Blending as a central process of grammar. In: GOLDBERG, Adele (ed.) (1993). Conceptual structure, discourse and language. Stanford: CSLI.

(2002). The way we think: conceptual blending and the mind's hidden complexities. New York: Basic Books.

GERHARDT, A. F. L. M. (2002). A semântica das construções gramaticais e o presente do Indicativo em português. Tese de Doutorado em Língua Portuguesa. Rio de Janeiro: UFRJ.

\& PINHEIRO, D.R. Locatividade, existência e posse na gramática do português. UFRJ. Inédito.

GIVÓN, T. (1984). Syntax: a funcional-typological introduction. Amsterdam/ Philadelphia: John Benjamins.

JOHNSON, M. (1992). The body in the mind: the bodily basis of meaning, imagination and reason. Chicago: University Press.

KARMILOFF-SMITH, A. (1992). Beyond modularity: a developmental perspective on cognitive science. Cambridge, MA: The MIT Press.

LAKOFF, G. (1987). Women, fire and dangerous things: what categories reveal about the mind. Chicago: University Press.

\& JOHNSON, M. (1980). Metaphors we live by. Chicago: University Press.

MIRANDA, N. S. (2000). A configuração das arenas comunicativas no discurso institucional: professores versus professores. Tese de Doutorado em Educação. Belo Horizonte: UFMG.

MITHEN, S. (2002). A pré-história da mente: uma busca das origens da arte, da religião e da ciência. São Paulo: Editora UNESP.

ORTONY, A. (ed.) (1993). Metaphor and thought. 2. ed. Cambridge: University Press.

QUARTZ, S. \& SEJNOWSKI, T.J. (1997). The neural basis of cognitive development: A constructivist manifesto. Behavioral and Brain Sciences 20 (4): 537-596.

ROSCH, E. (1973). On the internal structure of perceptual and semantic categories. In: MOORE, T. (ed.). Cognitive development and the acquisition of language. New York: Academic Press. (1978). Principles of categorization. In: ROSCH, Eleanor, Lloyd, B. B. (eds.) Cognition and categorization. Hillsdale, NS: Lawrence Erlbaum.

(1999). Reclaiming concepts. In: NUNEZ, R., FREEMAN, W. J. (eds.). Reclaiming cognition: the primacy of action, intention and emotion. Thorverton, Eng.: Imprint Academic.

ROZIN, P. (1986). The evolution of intelligence and access to the cognitive unconscious. In: SPRAGUE, J.M., EPSTEIN, A. N. (eds.). Progress in Psychobiology and Physiological psychology. New York: Academic Press. 
SALOMÃO, M. M. M. (1997). Gramática e interação: o enquadre programático da hipótese sócio-cognitiva sobre a linguagem. In: Veredas: revista de estudos lingüísticos. v.1, nº 1. pp. 23-39. Juiz de Fora: UFJF. (1998). O papel da gramática na construção do sentido. In: VALENTE, André (org.). Língua, Linguiística e Literatura. Rio de Janeiro: EDUERJ.

(1999). A questão da construção do sentido e a agenda dos estudos da linguagem. In: Veredas: revista de estudos lingüísticos. v. 3, no 1 . pp. 61/79. Juiz de Fora: UFJF.

SPERBER, D. The modularity of thought and the epidemiology of representations. In: HIRSCHFELD, L.A., GELMAN, S. A. (eds.). Mapping the Mind: domain specificity in cognition and culture. Cambridge: University Press.

TAYLO-R, J. R (1987). Linguistic categorization: prototypes in linguistic theory. Oxford: Clarendon Press.

TEIXEIRA, J. de F. (2000). Mente, cérebro e cognição. Petrópolis: Vozes.

TOMASELLO, M. (1999). The cultural origins of human cognition. Harvard: University Press. 